\title{
Study and Practice in Flipped Class Based on Inquiry Cooperative Learning
}

\author{
Shanshan Guo ${ }^{1, a^{*}}$, Qian Tian', b and Yun Liü, c \\ ${ }^{1}$ Weifang University, Weifang, China \\ ${ }^{2}$ Second primary school of Qiaoshan town, Juxian, China \\ alucy001478@163.com, b970607781@qq.com, cwflyun@qq.com
}

\section{Keywords: Inquiry; Cooperative learning; Flipping course; Vehicle engineering}

\begin{abstract}
At present, students born after 1995 has entered the university study and that born in the later five years are going to enter the University. This group of students has distinct personality. The traditional teaching mode has been unable to meet the development of students' innovative ability and the improvement of comprehensive quality to some extent. A new round of education reform, the flipped classroom has a rapid development, to a certain extent in favor of the cultivation of innovative ability and knowledge comprehension and internalization, but the flip classroom methods and patterns cannot be stereotyped, and the existing model cannot fully applicable to all professional students, there is need for the design and reform of. Therefore, the "vehicle inspection and test" course as an example of the detailed teaching strategies for students' professional turnover of the school vehicle engineering analysis, design process of cooperative learning and teaching practice and summary analysis, inquiry results show that cooperative learning has a good effect in the flipped classroom, deepen the students' understanding and innovation ability. Also improve the ability of team work.
\end{abstract}

\section{Introduction}

Jon Bergmann, Aaron Sams recorded videos of PPT and audio in class in 2007 to help the students who were not in the class to keep up their classes. Eric Mazu carried out the practices in Harvard class by using the flipping classroom teaching model. The Stanford University put the teaching video on the Internet, and students can freely choose the learning time [1]. At the same time, the corresponding problems every 15 minutes were set to understand the students' study result. The teaching model has good results through the addition of social discussion and communication areas to improve the learning interest and learning effect [2,3]. A joint school district in California has developed a digital interactive teaching material, which has powerful multimedia functions, including sharing, note taking, animation and video. American primary and secondary schools have implemented the flipped classroom teaching mode. Students' failing rate has been declined, students' participation in classroom has been greatly improved, self-confidence has increased, and discipline violations have declined accordingly.

At present, the domestic practice of flipping the classroom began in 1980s, Jiangsu Mudu high school practiced flipping classroom teaching according to reform model of problem oriented [4]. Before class, teachers assigned tasks for the next lesson. In class, teachers check students' preview and focus on the depth and breadth of problems. Chongqing Jukui school [5] randomly uploaded the lesson plans and teaching video to the "cloud campus" service platform [6], students downloaded the learning tasks before class from the network, completed the corresponding self-testing, and discussed learning difficulties in group, the no solved the problems were consolidated and uploaded to the cloud platform. The teachers' network examined the students' learning processes and questions, redesigned the teaching content in time, and carried out the targeted teaching classroom. The teaching model changed the traditional face-to-face teaching model and had a better learning effect.

Based on this, this paper develops a way of cooperative learning and teaching mode in flipped classroom to reconstruct the existing design, focus on the development and application of flipping 
the classroom in the teaching practice, and strive to provide a new method for the teaching reform of the specialty; in practice, through the practice in the course of "auto detection and experiment", we timely discover the problem, modify and redesign the teaching methods to improve the teaching effect, cultivate students' active thinking, innovation ability, team cooperation ability and comprehensive quality.

\section{Course status of auto detection and experiment}

The teaching method of existing classroom is face-to-face teaching methods, which is teacher centered, student participation, namely, multimedia courseware and writing auxiliary. This method is consistent with the teaching method of college theoretical course, but with the changing mode of the development of network information technology and students learning, the drawbacks of the traditional methods is increasing such as fewer teaching methods, low student participation, passive learning, poor learning motivation, and lack of timely teaching feedback, which results in slower teaching effectiveness.

Especially college students born after 1995, have the characteristics of active thinking, high learning interest, strong creativity, fast network information and so on. The traditional single teaching mode can no longer satisfy their knowledge and internalization of knowledge. However, in the flipping class, the process of imparting knowledge is transformed into an autonomous learning process through the network information technology. The process of knowledge mastery and internalization is completed in the interaction and collaboration with the teachers and other students in the classroom. The consolidation process is completed through the network review test after class. This teaching method greatly improves the initiative and enthusiasm of the students.

\section{The overall design of the flipped class based on inquiry cooperative learning}

Based on the analysis of the above curriculum status, the application of flipped classroom is carried out in inquiry learning cooperative learning for 2015 level vehicle engineering students during the second semester of the 206-2017 academic year. The overall plan of inquiry cooperative learning flipped classroom is designed. As shown in Fig.1, three steps are mainly discussed: analysis-design-implementation. On the basis of in-depth analysis of the existing teaching mode and its advantages and disadvantages, in-depth interviews with the students' learning needs and common personality characteristics, and repeated discussions, consultation and summary of learning methods and teaching strategies of flipped classroom with peers. Then the teaching content, cooperative learning methods and teaching mode are designed, curriculum evaluation system is established. Finally, the cooperative learning of flipping the classroom is implemented, after class, the teaching plan is interviewed, modified and optimized timely according to the feedback results and contents.

Inquiry cooperative learning is divided three stages: pre-class preview stage, classroom group collaboration stage and after-school interaction stage. In the process of learning, these three stages are complementary and mutually reinforcing relations.

The characteristics of this teaching method are that teachers set up problems and learning contents, so that students can complete their learning tasks independently or group cooperation through various learning resources, in order to full play the students' learning initiative and enthusiasm. Learning autonomy or group to complete learning materials screening, screening, induction and summary, conscious knowledge system construction and reconstruction, so as to better understand and master knowledge. The design concept is based on problems, task, cooperative inquiry to provide students with independent learning and teamwork platform and master the learning skills of active thinking and active learning. 


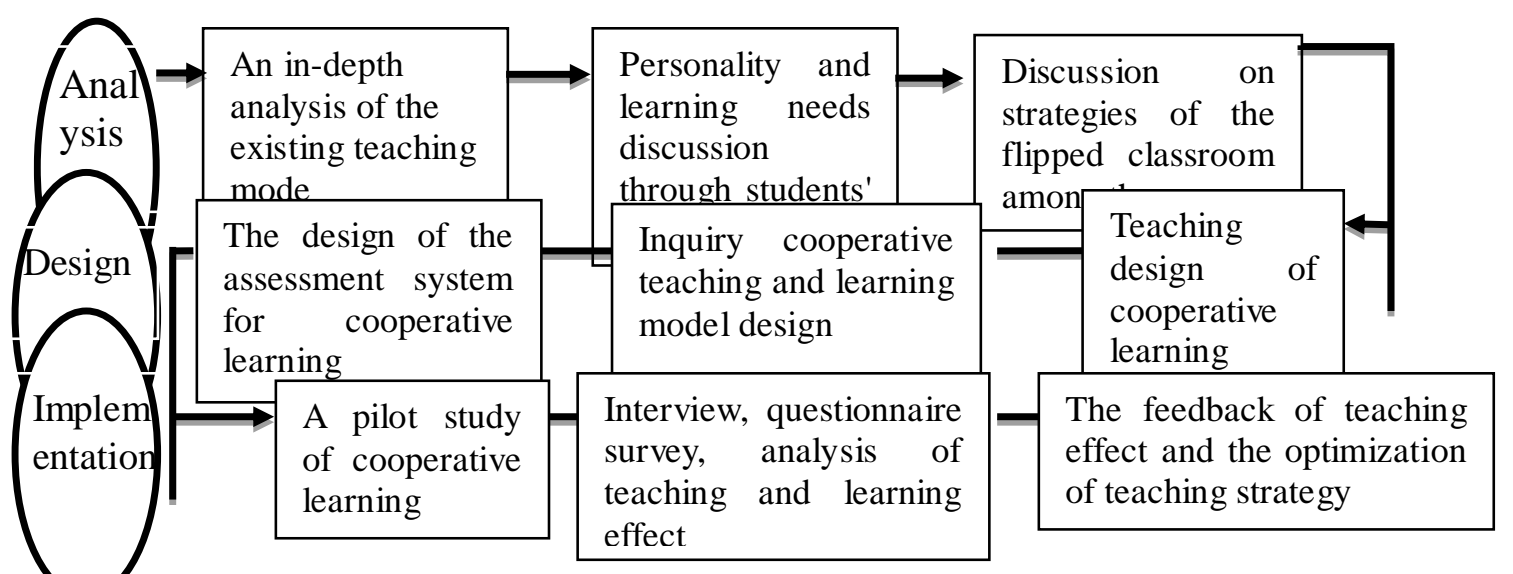

Figure 1. The overall design of the flipping class in inquiry cooperative learning

\section{The practice of flipped class based on inquiry cooperative learning}

During the second semester of the 2016-2017, the application practice of inquiry cooperative learning is carried out. The specific implementation process is as follows:

\section{Pre-classroom learning stage}

Before class, according to feedback and students' level, the teachers develop the tasks and questions and upload to the network teaching platform a week earlier. The main learning contents are in forms of multimedia courseware, video, animation and so on. Students learn network course contents autonomously. When encountering problems in the study, they can consult the group members to solve the problems. The unanswered questions are unified in the group and feedback to the network teaching platform. Then, the teachers modify the teaching content, revise the teaching objectives and prepare for the teaching.

\section{Class learning stage}

In face-to-face teaching classroom, teachers randomly check students' learning results, so as to master learning and progress and knowledge mastery, raise questions of student feedback, set up discussion contents, regroup, and carry out inquiry learning collaboration. Finally, the groups sent representatives to show the results of the discussion, and the members in the groups could make a corresponding supplement, and the other groups could raise questions or make different opinions in order to promote the internalization of students' professional knowledge and to exercise self-confidence, language expression and logical thinking ability. At this stage, teachers play a leading role in guiding students to think, timely guide and impart knowledge, and guide inquiry process, so as to prevent discussions from deviating from the theme, ensure the learning process carried out smoothly and achieve the desired learning effect.

\section{Communication stage after class}

After class, teacher chat with students to inquire students' evaluation of the learning process, review timely and summary of the whole teaching process, including pre-class learning, students' network feedback, re-design of learning process, reflection summary and preparation of the next section.

\section{Conclusion}

Based on a comprehensive analysis of the characteristics and existing teaching modes of the students, a flipped classroom teaching strategy based on inquiry cooperative learning is proposed, the overall teaching plan is designed. Taking the automobile test and experiment as an example, a series of curriculum practice has been implemented. At the same time, according to the feedback of the teaching effect, the course practice process is optimized and evaluated in time. The results show that the teaching strategies can improve the learning effect and enhance students' autonomous learning, active thinking, promote the knowledge internalization and fundamentally achieve the 
desired goal, further confirms the uniqueness of the teaching methods, which can be further practiced in related courses.

\section{References}

[1]. Long Han. College English project-based flipped classroom teaching design and Empirical Study of J Chinese education., 2015( 12) : $229-230$.

[2]. Wang Guoliang, Wang Huaqiao, Guo Kaihua. Blended learning anatomy flipped classroom teaching design and practice of $\mathrm{J}$ based on China education of medical technology. , 2015, 6

[3]. Herreid C, Schiller N. Case studies and the flipped class-room[J]. Journal of College Science Teaching, 2013, 42 (5) : 62.Information on: http://emc2016.boshuo.org/

[4]. Chen Jianmin. Research on the teaching mode under the concept of high school mathematics concept teaching [D]. Sichuan Normal University, 2015.

[5]. Zhang Lingyun. Study on student participation in the project type flipping classroom teaching model [D]. Huazhong Normal University,2015.

[6]. Tian Aili Application of inquiry teaching in flipped classroom -- Taking the flip classroom teaching in science and project design as an example, [J]. education development research.2015, 20: $39-4$. 